\section{AL-AZHAR}

Assiut Dental Journal
The Official Publication of The

Faculty of Dental medicine.

Al-Azhar Assiut Uniuersity.

Egypt

\title{
A Comparative Study of The Effect of Demineralized Bone Matrix with and Without Low Level Laser Therapy on The Treatment of Periodontal Infra-Bony Defects (Randomized Clinical Trial)
}

\author{
Mostafa S Gamil $^{* 1}$, Mahmoud T El-Destawy ${ }^{1}$, Mohamed M Fekry ${ }^{1}$
}

Codex : 08/1901

Aadj@azhar.edu.eg

\section{KEYWORDS}

DBM, LLLT, Intrabony Defect, $C A L$, periodontitis

1. Department of Oral Medicine, Periodontology, Oral Diagnosis, and Dental Radiology, Faculty of Dentistry, Al-Azhar University ,Cairo ( Boys).

* Corresponding author e-mail: mostafagamil.9@azhar.edu.eg

\begin{abstract}
Objective: This study aimed at comparing clinically and radiographically the therapeutic effect of low level laser therapy and demineralized bone matrix, used in management of periodontal intrabony defect. Subjects and methods: Thirty two non-smoking patients aged between 28-51 years with severe chronic periodontitis participated in this randomized clinical study. Patients were randomly assigned into one of 2 groups (16 patients each): demineralized bone grafting alone of the intrabony defect, control group (Group I), demineralized bone grafting and the application of low level laser therapy (LLLT) (Group II). Clinical and radiographic parameters including plaque index, bleeding index, probing depth, clinical attachment level (CAL) and intrabony defect depth were reassessed at 6 months after surgery. Results: Specifically, LLLT treated sites (Group II) showed statistically significant differences regarding pocket depth and CAL compared with Group I. Intrabony defect depth was significantly reduced for LLLT group compared to that of Group I control. Conclusion: The use of LLLT as an adjunct with demineralized bone matrix (DBM) in the treatment of intrabony defects was more significant in improving the probing depth, CAL and intrabony defect depth than using DBM alone.
\end{abstract}

\section{INTRODUCTION}

The main goal of periodontal treatment is to control infection and thereby suppress disease progression. Ideally, periodontal therapy includes not only suppressing the disease but also regeneration of tissues lost due to periodontal disease ${ }^{(1)}$. Different treatment modalities, such as guided tissue regeneration (GTR), the use of graft materials, or the application of growth factors, have been introduced to promote the regeneration of periodontal tissues and intrabony defects in $\operatorname{particular}^{(2,3)}$.

Complete periodontal regeneration is unpredictable with any regenerative therapy currently used, so, periodontal bone grafts show 
strong potential. A large body of clinical evidence clearly indicates that grafts consistently lead to better bone fill than non-grafted controls ${ }^{(4)}$. Demineralized bone matrix (DBM) have repeatedly demonstrated significant improvements in clinical parameters of the soft and hard tissue for the treatment of intraosseous periodontal defects. Substances present in the demineralized bone graft material, i.e., bone morphogenic proteins, stimulate local cell cycles to produce new bone. These factors enhance periodontal regeneration and/or bone fill ${ }^{(5)}$.

Studies commonly investigated the effect of low level laser therapy (LLLT) on cell cultures and remodeling of the tissue. It was suggested that, LLLT can increase quantity of adenosine triphosphate and simplify angiogenesis and collagen synthesis and alter behaviour of cellular activity by affecting the mitochondrial respiratory chain or membrane calcium channels ${ }^{(6,7)}$. It has been reported that laser enhanced biostimulation can induce intracellular metabolic changes, result faster cell division, proliferation rate, migration of fibroblasts and matrix production and also be effective on repair and regeneration of bone metabolism ${ }^{(8,9)}$. Once the DBM is placed in the osseous defect, a sequential differentiation of mesenchymal-type cell occurs promoting osteoblastic proliferation and differentiation. Low level laser therapy induces migration of fibroblast, rapid matrix production and increases local blood flow, which enhance the supply of circulating cells, nutrition, oxygen and inorganic salts to the bone defect ${ }^{(10)}$. LLLT may improve the regenerative effects by stimulating osteoblastic cell differentiation from progenitor stem cells ${ }^{(11)}$.

With the above mentioned background and the knowledge, the present Randomized Clinical Trial was conducted to compare clinically and radiographically the therapeutic effect of low level laser therapy and demineralized bone matrix, used in management of periodontal intrabony defect.

\section{SUBJECTS AND METHODS}

Thirty two non-smoking patients with age ranging from 28-51 years at the time of baseline examination (with mean $39.5 \pm 3.9$ ) with severe chronic periodontitis participated in this randomized clinical study. Subjects were selected from the list of patients seeking periodontal treatment at the Department of Oral Medicine, Periodontology, Oral Diagnosis and Oral Radiology, Faculty of Oral and Dental Medicine, Al Azhar University, Cairo, Egypt.

The criteria implemented for patient inclusion were: 1) according to dental modified Cornell Medical Index (12) no systemic diseases which could influence the outcome of therapy; 2) good compliance with plaque control instructions following initial therapy; 3) teeth involved were all vital with no mobility ; 4) each subject contributed a single predominately 2 or 3-wall intrabony defect around premolar or molar teeth; 5) selected intrabony defects (IBD) measured from the alveolar crest to the defect base in diagnostic periapical radiographs of $\geq 3 \mathrm{~mm}$ and width of $\geq 3 \mathrm{~mm}$ near to coronal part, with no cratering that involve both mesial and distal surfaces of adjacent teeth; 6) selected Probing Depth (PD) $\geq 5 \mathrm{~mm}$ and CAL $\geq 4 \mathrm{~mm}$ at the site of intraosseous defects four weeks following initial cause-related therapy; 7) availability for the follow-up and maintenance program; 8) absence of periodontal treatment during the previous year. Pregnant females, smokers and patients under corticosteroid therapy or immunocompromised patients were excluded from participating in the study. The study protocol was submitted and approved by the Ethical Committee of Al Azhar University. Research procedures were explained to all patients and they agreed to participate in the study and signed the appropriate informed consent form of Al Azhar University.

\section{Presurgical Therapy}

Initial cause-related therapy consisted of thorough full mouth scaling and root planning 
performed in quadrants under local anesthesia. This procedure was performed using a combination of hand and ultrasonic instrumentation and then patients got detailed mechanical plaque control instructions. Four weeks following initial therapy, a reevaluation was performed to confirm periodontal surgery indication.

Criteria implemented to indicate that surgery was necessary included the persistence of an interproximal site with $\mathrm{PD} \geq 5 \mathrm{~mm}, \mathrm{CAL} \geq 4$ $\mathrm{mm}$, and interproximal IBD of $\geq 3 \mathrm{~mm}$. Baseline periodontal disease status of the selected sites were determined by clinical assessments of plaque index, bleeding index, PD and CAL as the distance from the bottom of the pocket to the gingival margin and the cementoenamel junction (CEJ), respectively. The deepest point of the selected defect was selected in the calculations. Periapical views using intraoral size 2 dental films were taken and the intrabony defect depth of the selected sites were recorded from them (Fig 1).

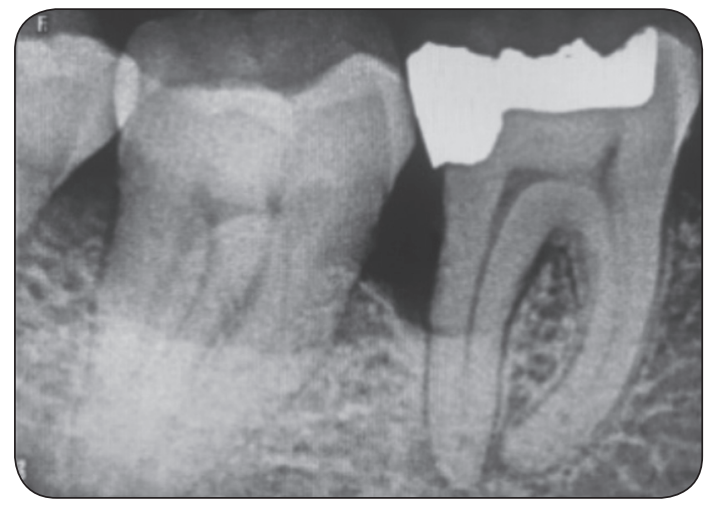

Fig.(1): The depth of the osseous defect from periapical radiograph.

\section{Grouping}

Patients were randomly assigned into one of a 2 groups (16 patients each): receiving open flap debridement + demineralized bone matrix alone control group (Group I), open flap debridement + demineralized bone matrix + low level laser therapy test group (Group II). Computer assessed randomization was carried out using a commercially available computer software package* immediately before surgery.

\section{Surgical Procedures}

The surgical treatment phase was initiated only if the subjects had a full-mouth dental plaque score of less than one and test site plaque score of 0 . After administration of local anesthesia, buccal intrasulcular incisions and 2- to 3-mm mucoperiosteal flap reflections were performed. Care was taken to preserve as much interproximal soft tissue as possible. For better access to the surgical site or to achieve better closure, the flap was extended one or two teeth mesially or distally in most cases. The periodontal surgical procedure fully exposed the intrabony defects.(Fig 2) Following mucoperiosteal flap reflection, all granulation tissue was removed from the defects by means of Gracey $7 / 8$ metal curettes** and root surfaces were scaled and planned using hand and ultrasonic instruments, The surgical sites were irrigated with sterile saline and care were taken to keep the area free of saliva.

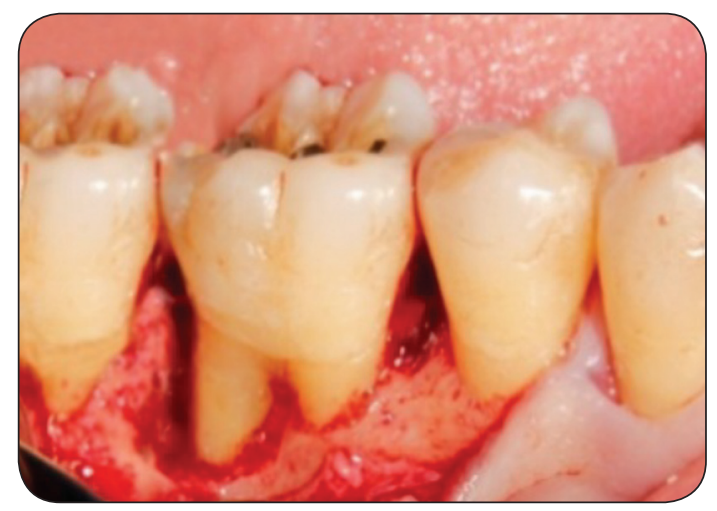

Fig.(2): Fully exposed intrabony defect.

\footnotetext{
* NCSS-PASS®, Number Cruncher Statistical Systems, Kaysville, UT, USA

** Healthcare, USA

*** Lasotronix Smart M Pro, Poland
} 
For group I, DBM was condensed into the intra bony defects up to the vertical height of the corresponding adjacent bone level, finally, the mucoperiosteal flaps were repositioned and secured in place using 3-0 silk suture utilizing an interdental, direct suturing technique achieving primary closure. Care were taken not to displace the graft material during suturing.

For group II, the defect was treated with laser application as follows: diode laser*** with wavelength $635 \mathrm{~nm}$, power $100 \mathrm{~mW}$, energy $2 \mathrm{~J} / \mathrm{cm} 2$ was delivered for 5 minutes, in continuous wave contact mode to the inner margins of flap at an angle of 45 degrees $^{(13)}$. Later, the defect was irradiated with LLLT in continuous non-contact mode for 10 minutes (Fig 3) ${ }^{(14)}$. DBM was then used to fill the defect site, and sutures were placed. The patient was recalled for the next five days and LLLT was performed for 5 minutes on the outer surfaces of the flaps. All patients received oral and written postoperative instructions. Patients were prescribed amoxicillin (500 mg) every 8 hours for 1 week.

Plaque control effort was supplemented by rinsing with $0.12 \%$ chlorhexidine gluconate for one minute 2 times daily for 2 weeks. Patients were instructed to refrain from brushing and interdental cleaning was avoided for the surgical areas during this time. Sutures were removed 2 weeks postoperatively and recall appointments for observation of any adverse tissue reaction and oral hygiene reinforcement were scheduled every second week during the first 2 months after surgery. Three weeks after surgery, all patients were instructed to resume their normal mechanical oral hygiene measures, which consisted of brushing using a soft toothbrush with a rolltechnique and flossing. Supportive periodontal maintenance, including oral hygiene reinforcement and supragingival scaling, was performed during each recall appointment. Clinical and radiographic measurements were reassessed at 6 months after surgery.

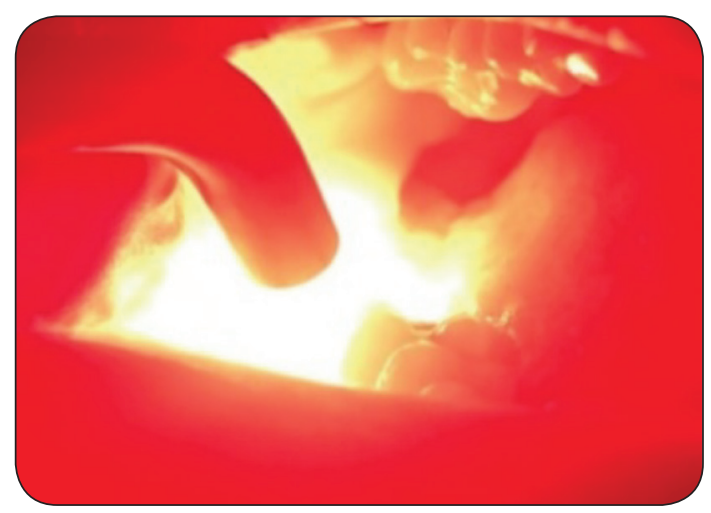

Fig.(3): LLLT application

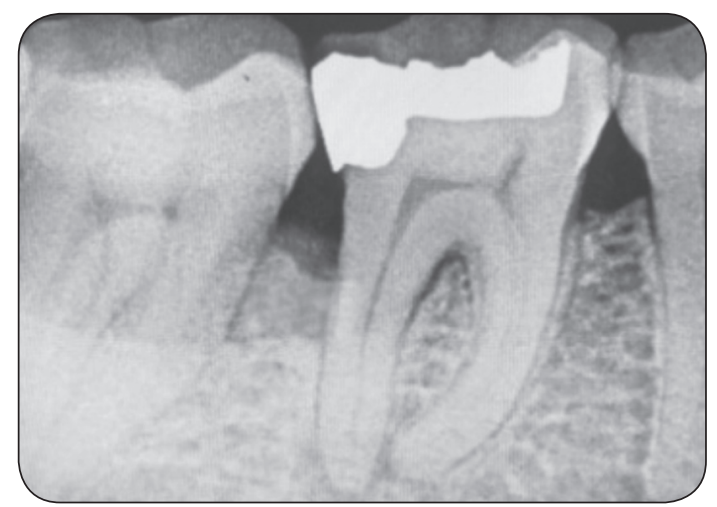

Fig.(4) Periapical radiograph taken 6 months after treatment

\section{RESULTS}

\section{Statistical analysis of the data}

Power analysis indicated 32 subjects (male and female) would be sufficient to demonstrate statistical significance with a power of (at least) $\geq$ $80 \%$. According to the following formula: $P D, n=2$ $*(\mathrm{z} \alpha+\mathrm{z} \beta)^{2}(\mathrm{SD})^{2} /(\mathrm{d})^{2}$ where $\mathrm{SD}=2$ and $\alpha=0.05$. Data were fed to the computer and analyzed using IBM SPSS software package version 20.0. (Armonk, NY: IBM Corp).The KolmogorovSmirnov test was used to verify the normality of distribution Quantitative data were described using range (minimum and maximum), mean, standard deviation and median. Mann Whitney test was used to compare two groups for abnormally distributed quantitative variables while Wilcoxon test was used to compare two periods. Significance of the obtained results was judged at the $5 \%$ level. 


\section{Plaque index}

At baseline, after 6 months; there was no statistically significant difference between plaque index in the two groups. Table (1)

\section{Bleeding index}

At baseline, after 6 months; there was no statistically significant difference between bleeding index in the two groups. Table (1)

\section{Probing depth}

At baseline; there was no statistically significant difference between probing depth in the two groups.

Table (1)

After 6 months; there was a statistically significant difference between probing depth in the two groups. Group II (DBM + Laser) showed a lower probing depth. Table (1)

\section{Clinical attachment level (CAL)}

At baseline; there was no statistically significant difference between CAL in the two groups. Table (1)

After 6 months; there was a statistically significant difference between CAL in the two groups. Group II (DBM + Laser) showed a lower CAL. Table (1)

\section{Intrabony defect depth}

At baseline; there was no statistically significant difference between intrabony defect depth in the two groups. Table (1)

After 6 months; there was a statistically significant difference between intrabony defect depth in the two groups. Group II (DBM + Laser) showed a lower intrabony defect depth. Table (1)

Table (1): Comparison between the two studied groups according to different parameters

\begin{tabular}{|c|c|c|c|c|}
\hline & $\begin{array}{c}\text { Group I } \\
\text { (DBM alone) }\end{array}$ & $\begin{array}{c}\text { Group II } \\
\text { (DBM + Laser) }\end{array}$ & $\mathbf{U}$ & $\mathbf{p}$ \\
\hline \multicolumn{5}{|l|}{ Plaque index } \\
\hline Baseline & $0.38 \pm 0.41$ & $0.36 \pm 0.33$ & 11.66 & 1.000 \\
\hline 6 Months & $1.0 \pm 0.37$ & $0.9 \pm 0.41$ & 9.89 & 0.312 \\
\hline $\mathrm{p}_{1}$ & 0.067 & 0.099 & & \\
\hline \multicolumn{5}{|c|}{ Modified bleeding index } \\
\hline Baseline & $0.48 \pm 0.4$ & $0.41 \pm 0.6$ & 11.55 & 1.000 \\
\hline 6 Months & $1.0 \pm 0.2$ & $0.85 \pm 0.5$ & 9.65 & 0.313 \\
\hline$p_{1}$ & 0.058 & $\mathbf{0 . 3 7 7}$ & & \\
\hline \multicolumn{5}{|l|}{ Probing depth } \\
\hline Baseline & $6.8 \pm 0.9$ & $6.5 \pm 0.8$ & 122.0 & 1.000 \\
\hline 6 Months & $2.9 \pm 0.7$ & $2.3 \pm 0.66$ & $72.44^{*}$ & $0.027^{*}$ \\
\hline $\mathbf{p}_{1}$ & $<0.001^{*}$ & $<0.001^{*}$ & & \\
\hline \multicolumn{5}{|l|}{ CAL } \\
\hline Baseline & $6.12 \pm 0.9$ & $6.01 \pm 0.8$ & 128.0 & 1.000 \\
\hline 6 Months & $3.4 \pm 0.9$ & $1.7 \pm 0.7$ & $2.99^{*}$ & $<0.001^{*}$ \\
\hline $\mathrm{p}_{1}$ & $<0.001^{*}$ & $<0.001^{*}$ & & \\
\hline \multicolumn{5}{|c|}{ Intrabony defect depth } \\
\hline Baseline & $5.5 \pm 0.8$ & $5.4 \pm 0.7$ & 89.0 & 0.161 \\
\hline 6 Months & $2.9 \pm 0.9$ & $0.9 \pm 0.5$ & $1.98^{*}$ & $<0.001^{*}$ \\
\hline $\mathbf{p}_{1}$ & $<0.001^{*}$ & $<0.001^{*}$ & & \\
\hline
\end{tabular}

U: Mann Whitney test

$p: p$ value for comparing between the two groups

p1: $p$ value for Wilcoxon signed ranks testfor comparing between baseline and 6 months

*: Statistically significant at $p \leq 0.05$ 


\section{DISCUSSION}

Autogenous bone is still the current gold-standard graft material for the treatment of bone defects. However, the need for a second surgical site has led to the development of different alternatives, such as the demineralized bone matrix ${ }^{(15)}$. Drawbacks of autogenous bone grafts such as donor site morbidity, ankylosis and localized root resorption could be overcome by DBM allograft, which has the capability to enhance new bone formation due to both osteoinductive and osteoconductive properties ${ }^{(16,17)}$. Histologically, DBM supports the formation of a new attachment apparatus in intrabony defects as they regenerate cementum, periodontal ligament and bone ${ }^{(18)}$.

Nowadays, Lasers have a multitude of applications, in the field of periodontology, such as the removal of tissues or hemostasis through their ability to enhance the cellular processes. Another important laser application is the low-power treatment, better known as LLLT. This process has been described as Low Laser Therapy or Low Intensity Laser Therapy. It relies on the ability of light to function as a photo-stimulant in living cells by exerting its effects through photoelectric, photophysical and photochemical phenomena ${ }^{(19)}$.

The present study evaluated the clinical efficacy of LLLT used with DBM for the treatment of IBD in patients with chronic periodontitis and showed significant radiographic bone fill and improvement in clinical parameters compared to control.

In the current study, there was no statistically significant change in both, plaque index and bleeding index in both groups. These results were similar to the results reported in a study by Calderin et al. where a therapy with a low-level diode laser $(670 \mathrm{~nm}, 200 \mathrm{~mW}, 60 \mathrm{~s} /$ tooth$)$, used in a single or repeated doses, did not produce a significant reduction in clinical parameters ${ }^{(20)}$. Also, Damante et al. reported that low-intensity laser therapy (diode; $670 \mathrm{~nm}, 15 \mathrm{~mW}, 4 \mathrm{~J} / \mathrm{cm} 2$ per point, four sessions for 1 week) did not accelerate oral mucosal healing after gingivoplasty ${ }^{(21)}$.
Statistically significant reduction in probing depth in group I and group II was seen after six months. Intergroup comparison revealed that statistically significant greater reduction in probing depth was recorded in group II after 6 months. This reduction correlates to the study conducted by Qadri et al. which examined the effect of low-level laser therapy following scaling and root planning. Irradiation with both $635-\mathrm{nm}(10 \mathrm{~mW}, 90 \mathrm{~s}, 0.9 \mathrm{~J})$ and $830-\mathrm{nm}(70 \mathrm{~mW}, 25 \mathrm{~s}, 1.75 \mathrm{~J})$ diode lasers to the external surface of gingiva was performed 1 week later and was continued once a week for 6 weeks. The clinical variables (i.e. probing pocket depth) were reduced more on the laser side than on the placebo side. The authors concluded that additional treatment with low-level lasers reduced gingival inflammation ${ }^{(22)}$.

Reduction in CAL in both groups was seen after 6 months which was statistically significant. Intergroup comparison revealed that group II showed lower CAL than group I after 6 months and this difference was statistically significant. This reduction is similar to the findings of the study done by Smiti Bhardwaj et. al, a diagnosed periodontitis stage III with an intrabony defect and the surgical treatment included the use of LLLT and bone graft, it was concluded that the combined approach of LLLT and demineralized bone matrix showed a positive outcome with CAL gain, reduction in periodontal probing depth (PPD) and linear bone gain and bone fill radiographically. This combination approach was safe and can be used for periodontal regeneration. LLLT can be used as a safe and effective adjunctive therapy with conventional surgical therapies aiming at accelerated healing along with periodontal regeneration ${ }^{(23)}$.

The present study showed statistically significant reduction in intrabony defect depth (radiographic interpretation) in both groups after 6 months. Intergroup comparison revealed that greater reduction in intrabony defect depth after 6 months was recorded in group II, which was found to be statistically significant. This outcome 
is similar to that of the study conducted by Park et al. which reported that low-level irradiation with a diode laser had positive effects on bone healing of extraction sockets in rats by increasing expression of the genes encoding Runx2, collagen type 1, osteocalcin, platelet-derived growth factor-B and vascular endothelial growth factor. They concluded that low level irradiation with a diode laser is beneficial in the early stages of alveolar bone healing ${ }^{(24,25)}$.

A study by de Oliveira et al, investigated the effect of low-level laser therapy on autogenous bone graft and concluded that LLLT stimulated bone regeneration and accelerated the process of integration of autogenous bone graft ${ }^{(26)}$. Lowlevel laser therapy has been reported to promote osteogenesis. Ozawa et al. (27) and Stein et al. (28) reported that low-level laser irradiation could promote bone nodule formation by inducing the proliferation and differentiation of osteoblasts.

With regard to the treatment of periodontal bone defects, Nagata et al. ${ }^{(29)}$ analyzed the influence of platelet-rich plasma, low-level laser therapy (660-nm diode laser), separately or combined, on the healing of periodontal fenestration defects in rats. Low-level laser therapy and platelet-rich plasma, separately or combined, all promoted new cementum formation with a functional periodontal ligament.

\section{CONCLUSION AND RECOMMENDATIONS}

Within the limits of the present study, we can conclude that, that the use of LLLT as an adjunct with DBM in the treatment of intra-bony defects was more significant in improving the probing depth, CAL and intrabony defect depth than using DBM alone.

Further studies are needed to try different doses of LLLT to improve the initial stage of bone healing and regeneration.

\section{REFERENCES}

1. Karring T, Lindhe J, Cortellini P. Regenerative periodontal therapy. In: Lindhe J, Karring T, Lang NP, eds. Clinical Periodontology and Implant Dentistry, 4th ed. Oxford, UK: Blackwell Munksgaard; 2003:650-704.

2. Sculean A, Schwarz F, Chiantella GC, et al. Five-year results of a prospective, randomized, controlled study evaluating treatment of intra-bony defects with a natural bone mineral and GTR. J Clin Periodontol 2007;34:72-7.

3. Cortellini P, Tonetti MS. Minimally invasive surgical technique and enamel matrix derivative in intra-bony defects. I: Clinical outcomes and morbidity. J Clin Periodontol 2007;34:1082-8.

4. Rosenberg E, Rose LF. Biologic and clinical considerations for autografts and allografts in periodontal regeneration therapy. Dent Clin North Am. 1998;42:467-90.

5. Piemontese M, Aspriello SD, Rubini C, Ferrante L, Procaccini M. Treatment of periodontal intrabony defects with demineralized freeze-dried bone allograft in combination with platelet-rich plasma: A comparative clinical trial. J Periodontol. 2008;79:802-10.

6. Marques MM, Pereira AN, Fujihara NA, Nogueira FN, Eduardo CP. Effect of low-power laser irradiation on protein synthesis and ultrastructure of human gingival fibroblasts. Lasers Surg Med. 2004;34:260-5.

7. Pereira AN, Eduardo CP, Matson E, Marques MM. Effect of low-power laser irradiation on cell growth and procollagen synthesis of cultured fibroblasts. Lasers Surg Med. 2002;31:263-7.

8. AboElsaad NS, Soory M, Gadalla LM, Ragab LI, Dunne $S$, Zalata KR, et al. Effect of soft laser and bioactive glass on bone regeneration in the treatment of bone defects (an experimental study). Lasers Medical Sci. 2009;24:527-33.

9. Ozcelik O, Cenk HM, Seydaoglu G. Enamel matrix derivative and low-level laser therapy in the treatment of intra-bony defects: a randomized placebo-controlled clinical trial. J Clin Periodontol. 2008;35:147-56.

10. Kreisler M, Christoffers AB, Al-Haj H, Willershausen B, d'Hoedt B. Low level 809nm diode laser-induced in vitro stimulation of the proliferation of human gingival fibroblasts. Lasers Surg Med. 2002;30(5):365-9.

11. Wu JY, Chen CH, Yeh LY, et al. Low-power laser irradiation promotes the proliferation and osteogenic differentiation of human periodontal ligament cells via cyclic adenosine monophosphate. Int J Oral Sci. 2013;5(2):85-91. 
12. Abramson GH. The Cornell medical index as an epidemiological tool. Am J Public Health 1966;65:287-98.

13. Sanz-Moliner JD, Nart J, Cohen RE, Ciancio SG. The effect of an 810-nm diode laser on postoperative pain and tissue response after modified Widman flap surgery: a pilot study in humans. J Periodontol. 2013;84(2):152-8.

14. Rasouli Ghahroudi AA, Rokn AR, Kalhori KA, et al. Effect of low-level laser therapy irradiation and bio-oss graft material on the osteogenesis process in rabbit calvarium defects: a double blind experimental study. Lasers Med Sci. 2014;29(3):925-32.

15. Campana V, Milano G, Pagano E, Barba M, et al. Bone substitutes in orthopaedic surgery: from basic science to clinical practice. J Mater Sci Mater Med. 2014;25(10):2445-61.

16. Abolfazli N, Saleh SF, LAfzi A, Eskandari A, Mehrasbi S. A Clinical Comparison of Cenobone (A Decalcified Freeze-dried Bone Allograft) with autogenous bne graft in the treatment of two- and three-wall intrabony periodontal defects: A human study with six-month reentry. 2008;2(1):1-8.

17. Shah M, Lobo Gajiwala A, Shah S, Dave D. Comparative study of indigenously prepared and imported, demineralized, freeze-dried, irradiated bone allograft in the treatment of periodontal infrabony defects. Cell and Tissue Banking. 2015;(16):371-9.

18. Reynolds MA, Aichelmann-Reidy ME, Branch-Mays GL, Gunsolley JC. The efficacy of bone replacement grafts in the treatment of periodontal osseous defects. A systematic review. Ann Periodontol. 2003;8(1):227-65.

19. Karoussis IK, Kyriakidou K, Psarros C, Koutsilieris M, Vrostos JA. Effects and Action Mechanism of Low Level Laser Therapy (LLLT): Applications in Periodontology. Dentistry. 2018; 8:514-9.

20. Calderin S, Garcia-Nunez JA, Gomez C. Short-term clinical and osteoimmunological effects of scaling and root planning complemented by simple or repeated laser phototherapy in chronic periodontitis. Lasers Med Sci. 2013;28:157-66.
21. Damante CA, Greghi SL, Sant'ana AC, Passanezi E. Clinical evaluation of the effects of low-intensity laser (GaAlAs) on wound healing after gingivoplasty in humans. J Appl Oral Sci. 2004;12:133-6.

22. Qadri T, Miranda L, Tuner J, Gustafsson A. The shortterm effects of low-level lasers as adjunct therapy in the treatment of periodontal inflammation. J Clin Periodontol. 2005;32:714-9.

23. Smiti B, Joann PG, Divakaran R, Divya K. Low level laser therapy in the treatment of intra-osseous defect- A case report. J of Clin and Diag Res. 2016;3: 6-8.

24. Park JB, Ahn SJ, Kang YG, Kim EC, Heo JS, Kang KL. Effects of increased low-level diode laser irradiation time on extraction socket healing in rats. Lasers Med Sci. 2013;30(2):719.

25. Park JH, Heo SJ, Koak JY, Kim SK, Han CH, Lee JH. Effects of laser irradiation on machined and anodized titanium disks. Int J Oral Maxillofac Implants. 2012;27:26572.

26. De Oliveira Gonçalves JB, Buchaim DV, de Souza Bueno CR, Pomini KT, Barraviera B, Júnior RS, et al. Effects of low-level laser therapy on autogenous bone graft stabilized with a new heterologous fibrin sealant. J Photochem Photobiol B. 2016;162:663-8.

27. Ozawa Y, Shimizu N, Kariya G, Abiko Y. Low-energy laser irradiation stimulates bone nodule formation at early stages of cell culture in rat calvarial cells. Bone. 1998;22:347-54.

28. Stein A, BenBenayahu D, Maltz L, Oron U. Low-level laser irradiation promotes proliferation and differentiation of human osteoblasts in vitro. Photomed Laser Surg. 2005; 23:161-6.

29. Nagata MJ, de Campos N, Messora MR, Pola NM, Santinoni CS, Bomfim SR, et al. Platelet-rich plasma, low level laser therapy or their combination promote periodontal regeneration in fenestration defects: a preliminary in vivo study. J Periodontol. 2014;85:770-8. 


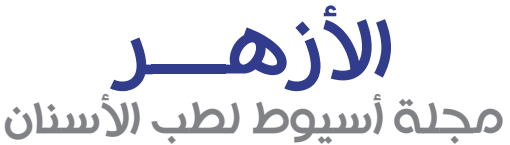

النشر الرسمي لكلية طب الأسنان

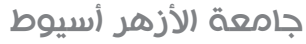

AADJ, Vol. 2, No. 1, APRIL (2019) - PP. 75:75

الملخص العربي

الردف

هدفت هذه الدراسـة إلى مقارنة التأثير العلاجي للعلاج بالليزر منخفض المستوى ومصفوفة العظام المنزوعة المعادن ، المستخدمة في علاج الفجـوات العظمية داخل اللثة العلة

المواضيع والأساليب

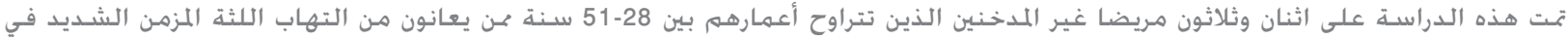

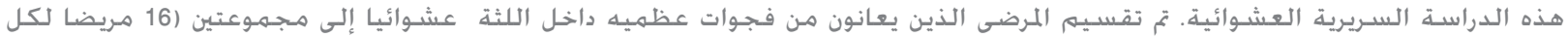

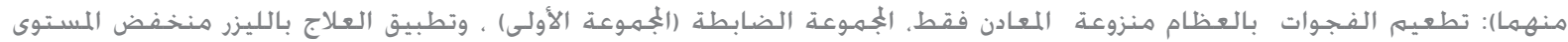

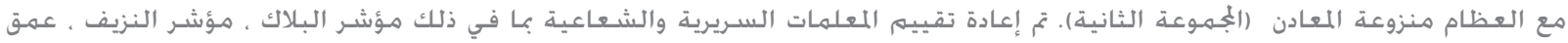

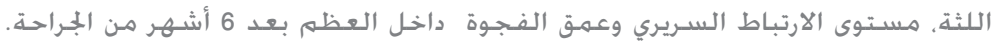

النتائج

أظهرت المواقع المعالجـة فـى الجمهموعة الثانية فروق ذات دلالة إحصائية فيما يتعلق بعمق الجيب و مستوى الارتباط السـريرى للثه مقارنةً

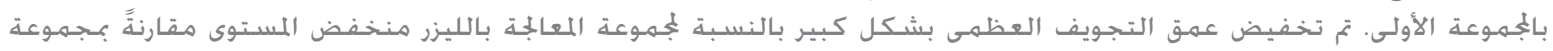
التحكم

الخلاصة

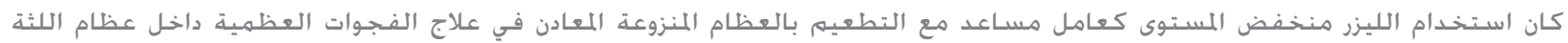

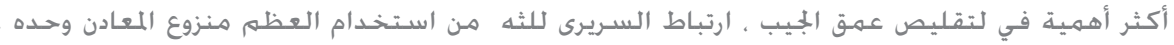

الكلمات (لمفتاحية:

التهاب اللثة , ليزر منخفض المستوى , فجـوات عظميه داخل اللثة , عظام منزوعة المعادن 